\title{
Fatty acids profile of Serra da Estrela PDO cheeses and respective atherogenic and thrombogenic indices
}

\author{
Maria João Reis Lima, Luisa Fontes, Hamdi Bahri, Ana C.A. Veloso, \\ Edite Teixeira-Lemos and António M. Peres \\ (Author affiliations can be found at the end of the article)
}

\begin{abstract}
Purpose - This study aims to determine the physicochemical and fatty acids composition of Serra da Estrela cheese (SEC), as well as health-related lipid indices, like the atherogenic and thrombogenic indices, and to evaluate the influence of producer, geographical origin and production date.
\end{abstract}

Design/methodology/approach - All 24 SEC produced between November 2017 and March 2018 were collected at selected certified producers and analyzed by NIR spectrophotometer and by GC. Data were statistically evaluated by chemometric tools.

Findings - In all evaluated SEC, 23 fatty acids were quantified. Cheese origin influenced nutritional and health-related lipid indices). The cheeses were characterized by a relative high abundance of saturated fatty acids $(67-76 \%)$, followed by a medium content of monounsaturated fatty acids (17-25\%) and by low level of polyunsaturated fatty acids $(5-7 \%)$. A putative positive association between cheese consumption and healthy lipid indices could be reached.

Practical implications - The contents of some medium and long chain fatty acids as well as of nutritional and health indices were influenced by cheese producer, geographical origin and production date pointing out the need for standardizing production procedures.

Social implications - The SEC plays a key role in the local economy, being an endogenous product with unique sensory characteristics and nutritional potential, for which the knowledge of the lipids profile and health indices is of utmost relevance.

Originality/value - SEC is an iconic Portuguese cheese with Protected Designation of Origin. Based on the results, like health-related lipid indices, evaluated for the first time, a positive association between cheese consumption and healthy lipid indices could be envisaged.

Keywords Atherogenic index, Fatty acids profile, Omega-6:omega-3 ratio, Serra da Estrela cheese, Thrombogenic index

Paper type Research paper

This work was financially supported by Associate Laboratory LSRE-LCM - UID/EQU/50020/2019, strategic funding UID/BIO/04469/2019-CEB and BioTecNorte operation (NORTE-01-0145-FEDER000004), and strategic project PEst-OE/AGR/UI0690/2014-CIMO funded by national funds through FCT/MCTES (PIDDAC). The authors would also like to acknowledge the funding provided by the approved Project, with reference 02/SAICT/2016/23290, entitled Characterization and Valorization of QSE PDO and its ability for health promotion (QCLASSE), financed by FCT.

Compliance with Ethics Requirements.

Conflict of Interest: The authors declare no conflict of interest. Ethical approval: This article does not contain any studies with human participants or animals performed by any of the authors.

Informed Consent: Not applicable.

Nutrition \& Food Science c) Emerald Publishing Limited 0034-6659 DOI 10.1108/NFS-06-2019-0178 


\section{Introduction}

Serra da Estrela cheese (SEC) is a Protected Designation of Origin (PDO) traditional Portuguese cheese produced from raw milk of autochthonous sheep ("ChurraMondegueira" and "Bordaleira"). SEC is the finest among the Portuguese traditional cheeses and is appreciated worldwide, being preferentially consumed as a soft cheese, with an average maturation of 30-45 days, although some consumers prefer to consume it as a hard cheese, after at least 6 months of storage (Carocho et al., 2015; Macedo and Malcata, 1996; Partidário et al., 1998). Its production is limited to the eponymous mountains in the centre of Portugal, in a specific region. It is manufactured using an aqueous extract of the wild thistle (Cynara cardunculus), without deliberate addition of any starter culture. Even though SEChas very precise and legally defined physicochemical and sensorial characteristics, many extrinsic factors may condition them. Among them we might consider the maintenance and the eating qualities of the "ChurraMondegueira" and "Bordaleira" sheep that might directly influence the milk chemical and microbiological characteristics and consequently the final cheese composition (Balthazar et al., 2017; Jaramillo et al., 2008; Sanz Sampelayo et al., 2007). The ecotypes of the wild thistle (Cynara cardunculus) (Correia et al., 2014) and the natural and heterogenous microflora associated with the processing and maturation, also contributes to the final characteristics of SEC.

In the EU as well as in Portugal two main diseases groups linked to the circulatory system, namely ischaemic heart diseases (also known as coronary heart diseases, including heart attacks) and cerebrovascular diseases (such as strokes) are the leading cause of death among adults. Therefore, awareness campaigns were developed in order to decrease the ingestion of sugar and fat by the population. Consequently, consumers have become more concerned about the food fat content. Producing cheese with an improved fatty acid (FA) profile and to know exactly the FA composition of endogenous and traditional cheeses could significantly increase economic returns to farmers (Vera et al., 2009). It is well known that in cheese we might found saturated fatty acids (SFA) like myristic and palmitic acids, which are usually related to the increase of blood plasma cholesterol concentration and for a growing incidence in coronary heart diseases (Legrand and Rioux, 2015; Lottenberg et al., 2012). In contrast, differences in metabolic handling of fatty acids may support that medium chain fatty acids (MCFA) hold potential as weight loss agents with unique nutritional and physiologic properties (Terada et al., 2012). Cheese fat also contains health-promoting components associated with unsaturated fatty acids (UFA) including conjugated linoleic acid (CLA), vaccenic, $\alpha$-linolenic and oleic acids and $n$ - 3 fatty acids, which contribute for the reduction of the risk of cardiovascular diseases, showing anticarcinogenesis, immunomodulation, and antiatherosclerosis properties as well as lean body mass-enhancing properties, beside inhibiting degenerative cellular proliferation and reduce obesity and cardiovascular diseases (Calder, 2013; Cockbain et al., 2012; Fattore and Massa, 2018). Also, the consumption of dairy products with lower values of atherogenic and thrombogenic indices (AI and TI, respectively) leads to a decrease in the total cholesterol and the LDL-cholesterol in human blood plasma (Hirigoyen et al., 2018; Poppitt et al., 2002).

Dairy products assumed an important position in Mediterranean diet; however, they are often correlated with cardiovascular diseases. Although some information about physicochemical, textural, sensorial and nutritional characteristics of SEC can be found (Reis Lima et al., 2019), knowledge about its variation among different producers, is rather scarce. It is therefore interesting, both for scientific and public health purposes, to evaluate nutritional aspects, regarding to fatty acid profile and its characterization considering the atherogenicity. Thus, the aim of the present study was to characterize the FA profile and the related health and nutritional lipid indices (AI, TI and $\Sigma(\omega-6) / \Sigma(\omega-3)$ values) of SEC from 6 
producers located in 5 geographical different points of the PDO denomination and to overcome the lack of information between the moment of production on the desirable, short chain saturated and medium chain saturated fatty acids (DFA, SCFA and MCFA, respectively) relative abundances.

\section{Materials and methods}

\subsection{Serra da Estrela cheese samples}

Twenty-four SECs (approximately 1 kg), produced between November 2017 and March 2018, with approximately 45 days of maturation, were collected at selected certified producers and immediately transported, in refrigerated boxes, to the laboratory, being then split in different portions, which were frozen $\left(-40^{\circ} \mathrm{C}\right)$ until analysis. The cheeses were produced with the milk, collected from ewes ("ChurraMondegueira" and "Bordaleira" autochthonous breeds) acquired in 6 certified cheese producers (coded as Producer 1 to 6) located in 5 municipalities within the delimited PDO region (Celorico da Beira - CB, Gouveia - G, Nelas - N, Oliveira do Hospital- OH and Penalva do Castelo - PC), belonging to 3 Portuguese districts, namely, Coimbra ( $\mathrm{OH}$, Producer 1), Guarda (CB, Producer 2 and G, Producer 5) and Viseu (N, Producer 6 and PC, Producers 3 and 4) districts (Portugal). In total, 48 independent samples were studied (two samples per cheese), according to: Producer $1-5$ cheeses $\times 2$ collected in November 2017, December 2017, January 2018, February 2018 and March 2018; Producer $2-3$ cheeses $\times 2$ collected in November 2017, February 2018 and March 2018; Producer $3-3$ cheeses $\times 2$ collected in December 2017 and March 2018; Producer $4-4$ cheeses $\times 2$ collected in December 2017, February 2018 and March 2018; Producer $5-5$ cheeses $\times 2$ collected in November 2017, January 2018, February 2018 and March 2018; Producer $6-4$ cheeses $\times 2$ collected in November 2017, December 2017, February 2018 and March 2018.

\subsection{Moisture, total fat, total protein and salt contents of Serra da Estrela cheeses: sample preparation and NIR analysis}

To expose the interior of the cheese, $1.5 \mathrm{~cm}$ of the rind was removed and a slice of approximately $100 \mathrm{~g}$ was placed in a flat-bottom glass cuvette and analyzed, in triplicate, on a NIRMaster ${ }^{\mathrm{TM}}$ spectrophotometer (Near Infrared Spectroscopy) from BuchiNIRSolutions ${ }^{\mathrm{TM}}$ (Flawil, Switzerland). Spectra were recorded in this instrument which is equipped with a polarization interferometer with $\mathrm{TeO}_{2}$ wedges, an extended range InGaAs detector (temperature controlled) working in diffuse reflectance with a spectral range of $800-2500 \mathrm{~nm}$ (resolution: $8 \mathrm{~cm}_{\mathrm{TM}}^{-1}$ ) combined with NIRWare ${ }^{\mathrm{TM}}$ software package, also from BuchiNIRSolutions ${ }^{\mathrm{TM}}$. A blank signal was previously obtained with external reference Spectralon ${ }^{\circledR}$. The internal background was measured with a gold plate reflector. Broad-based calibration was used in this study, which was previously adjusted with samples of SEC.

\subsection{Fatty acids profiles of Serra da Estrela cheeses: sample preparation and gas chromatography analysis}

Lipids were extracted following the International Standard Method described in ISO 14156:2001. Briefly, $0.5 \mathrm{~g}$ of each cheese sample (48 samples $=24$ cheeses $\times 2$ independent samples) were weighed and placed into a $10 \mathrm{~mL}$ vial, to which $5 \mathrm{~mL}$ of $n$-hexane were added plus $1 \mathrm{~mL}$ of a $\mathrm{KOH}-m$ ethanol solution $(5 \mathrm{~mol} / \mathrm{L})$. The mixture was then placed in an ultrasonic bath during $5 \mathrm{~min}$, after which it was allowed to stand for $5 \mathrm{~min}$ more at ambient temperature. This procedure was repeated 3 times, in order to ensure the formation of 2 immiscible phases. Then 8 drops of glacial acetic acid were added and the mixture was 
manually shaken during $1 \mathrm{~min}$. Then, the $n$-hexane phase was removed from the vial and filtered through a nylon filter ( $0.2 \mu \mathrm{m}$ from Millipore), and frozen until being analyzed by gas-chromatography (GC).

GC analysis of fatty acid methyl esters (FAME) was carried out in GC 1000 instrument from DANI equipped with a split/splitless injector, a flame ionization detector (FID) and a Zebron column (ZB-FAME from Phenomenex: $(30+5) \mathrm{m} \times 0.25 \mathrm{~mm} \mathrm{ID} \times 0.20 \mu \mathrm{m}$. The oven temperature was programmed as follows: the initial temperature of the column was $100^{\circ} \mathrm{C}$, held for $2 \mathrm{~min}$, then a $10^{\circ} \mathrm{C} / \mathrm{min}$ ramp was used until $140^{\circ} \mathrm{C}$, followed by a $3^{\circ} \mathrm{C} / \mathrm{min}$ ramp until $190^{\circ} \mathrm{C}$, then $30^{\circ} \mathrm{C} / \mathrm{min}$ ramp until reaching $260^{\circ} \mathrm{C}$ and held for $2 \mathrm{~min}$. The carrier gas (hydrogen) flow rate was $4.0 \mathrm{~mL} / \mathrm{min}(0.61 \mathrm{bar})$, measured at $50^{\circ} \mathrm{C}$. Split injection (1:59) was carried out at $250^{\circ} \mathrm{C}$, being the detector at $260^{\circ} \mathrm{C}$. A constant flow rate of $1 \mathrm{~mL} / \mathrm{min}$ was used. For each analysis $1 \mu \mathrm{L}$ of the sample was injected in GC equipment. The identification was carried out by comparing the relative retention times of the FAME to commercial standards (reference sample of FAME Mix Supelco 37 (C4-C24)). The quantification was achieved through CSW 1.7 (DataApex 1.7, Prague, Czech Republic). The results were expressed in relative percentage of each fatty acid.

\subsection{Lipid related health quality indices}

From the fatty acids profiles of cheeses, the contents (in per cent) of desirable fatty acids (DFA), which allowed assessing the content of beneficial fatty acids for health (Barać et al., 2018; Osmari et al., 2011; Taboada et al., 2015), short chain saturated fatty acids (SCFA) and medium chain saturated fatty acids (MCFA) were calculated as follows:

$$
\begin{gathered}
\text { DFA }=\Sigma M U F A+\Sigma P U F A+C_{18: 0} \\
S C F A=C_{4: 0}+C_{6: 0} \\
M C F A=C_{8: 0}+C_{10: 0}+C_{11: 0}+C_{12: 0}+C_{13: 0}+C_{14: 0}+C_{15: 0}
\end{gathered}
$$

The atherogenic index (AI) and thrombogenic index (TI), linking fatty acid profile to cardiovascular risk, were calculated according to Ulbricht and Southgate (1991):

$$
\begin{gathered}
A I=\frac{4 \times C_{12: 0}+C_{14: 0}+C_{16: 0}}{\Sigma M U F A+\Sigma P U F A} \\
T I=\frac{C_{14: 0}+C_{16: 0}+C_{18: 0}}{0.5 \times \Sigma M U F A+0.5 \times(\mathrm{PUFA}-n 6)+3 \times(\mathrm{PUFA}-n 3)+\frac{P U F A-n 3}{P U F A-n 6}}
\end{gathered}
$$

Finally, the $\Sigma(\omega-6) / \Sigma(\omega-3)$ ratio was also calculated, since a high intake of $\omega-6$ acids has been recognized to be undesirable, being a low ratio envisaged from a nutritional point of view (Aro et al., 2005; Garaffo et al., 2011; Simopoulos, 2002):

$$
\frac{\Sigma(\omega-6)}{\Sigma(\omega-3)}=\frac{P U F A-n 6}{P U F A-n 3}=\frac{C_{18: 2 \mathrm{n} 6 \mathrm{t}}+C_{18: 2 \mathrm{n} 6 \mathrm{c}}+C_{20: 4 \mathrm{n} 6}}{C_{18: 3 \mathrm{n} 3}}
$$




\subsection{Statistical analysis}

The effects of cheese producer, geographical origin and production season on Serra da Estrela fatty acids profiles as well as on health and nutritional indices (e.g. $\omega-6 / \omega-3$ ratio, atherogenic index, thrombogenic index, DFA, SCFA and MCFA) were evaluated through the one-way analysis of variance (one-way ANOVA), being the post-hoc multi-comparison Tukey's test further used if a significant statistical effect was found $(\phi<0.05)$. Furthermore, for the health and nutritional indices, the results were graphically evaluated using boxplots. All statistical analysis was performed using the Subselect (Cadima et al., 2004, 2018) and MASS (Venables and Ripley, 2002) packages of the open source statistical R programme (version 2.15.1), at a 5 per cent significance level.

\section{Results and discussion}

\subsection{Serra da Estela cheese moisture, total fat, total protein and salt contents: changes with} producer, location and moment of manufacturing

The mean values of moisture, total fat, total protein and salt contents per producer, geographical origin or moment of production are shown in Tables I to III. Results showed that, the producer, geographical origin and the moment of manufacturing significantly influenced the contents of the above mentioned chemical parameters $(\phi \leq 0.007$, one-way ANOVA). In brief, cheeses from Producer \#3 and \#6 had the highest moisture content and the lowest total fat, total protein and salt levels. On the other hand, cheeses produced in January 2018 showed the lowest moisture content and the highest total fat content. Oppositely, Guiné et al. (2016) did not found any significant effect of the producer neither of the geographical origin on the moisture content. Regarding the fat content, it was highly dependent on the geographical origin but not on the producer. For the protein content, those researchers found a significant effect of both producer and geographical origin. Salt contents significantly varied between producer and geographical origin. In fact, in the present study it was observed that, depending on the fixed effect under evaluation, moisture content varied in the range of 44-52 per cent, total fat from 20 to 30 per cent, total protein between 1925 per cent and finally, salt content ranges from 0.9 to 1.8 per cent. The moisture contents were within the values legally established (DR $42 / 85$ of 05th July that fixed a range between 61-69 per cent referred to fat free cheese), and similar to the contents reported by Macedo et al. (2004), Guiné et al. (2016) and Carocho et al. (2016b) for SECs. The fat contents found were similar to those determined by Macedo et al. (2004) and Carocho et al. (2016a). The total protein levels found in this work were higher compared to those reported by Macedo et al. (2004) but in the same order of values reported by Guiné et al. (2016) and Carocho et al. (2016a, 2016b). Finally, salt contents were similar of those reported by Guiné et al. (2016) and slightly higher than those observed by Macedo et al. (2004). These findings pointed out that, although the production region of this traditional ewe PDO cheese is limited and its production is legally regulated, different cheese compositions have been reported in the literature, showing the high chemical variability of SEC.

\subsection{Effects of producer's location and moment of production in lipidic profile of Serra da}

Estrela cheese

Free fatty acids (FFA) play an important role in flavours of many varieties of ripened cheese. The two major sources for FFA in ripened cheese are:

(1) the end products of carbohydrate and protein metabolism by bacteria; and

(2) the direct breakdown products of milk fat by lipolysis. 
NFS

Table I.

Physicochemical data and main fatty acids found in SECs (mean \pm standard deviation) produced by 6 certified producers (producers 1 to 6$)$ at 5 geographical origins located within the PDO region, from November 2017 to March 2018

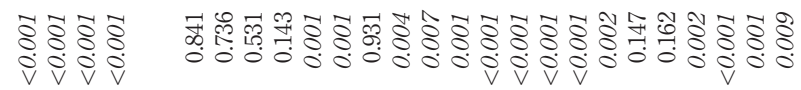

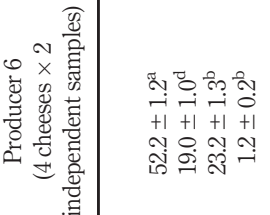

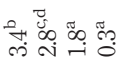

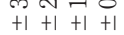

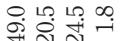

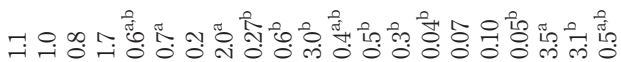
$+1+1+1+1+1+1+1+1+1+1+1+1+1+1+1+1+1+1+1+1+1$

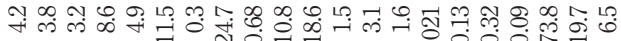

تำ

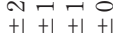
N 0.00 .00$.

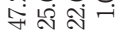

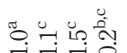
$+1+1+1+1$ 它

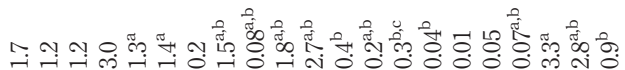
$+1+1+1+1+1+1+1+1+1+1+1+1+1+1+1+1+1+1+1+1+1$

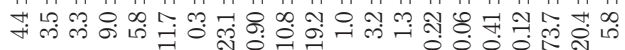

(1)

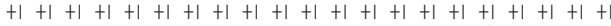

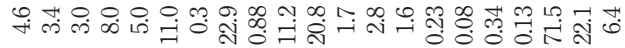

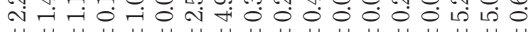
ๆ

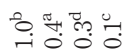

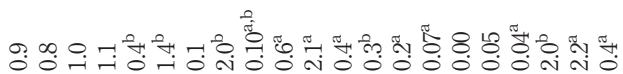
$+1+1+1+1+1+1+1+1+1+1+1+1+1+1+1+1+1+1+1+1+1$

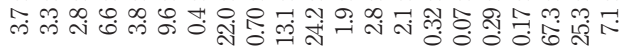

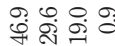

तi

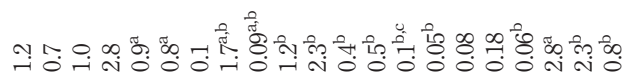
$+1+1+1+1+1+1+1+1+1+1+1+1+1+1+1+1+1+1+1+1+1$

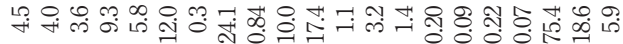
(1)

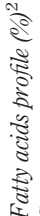

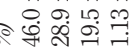
. 


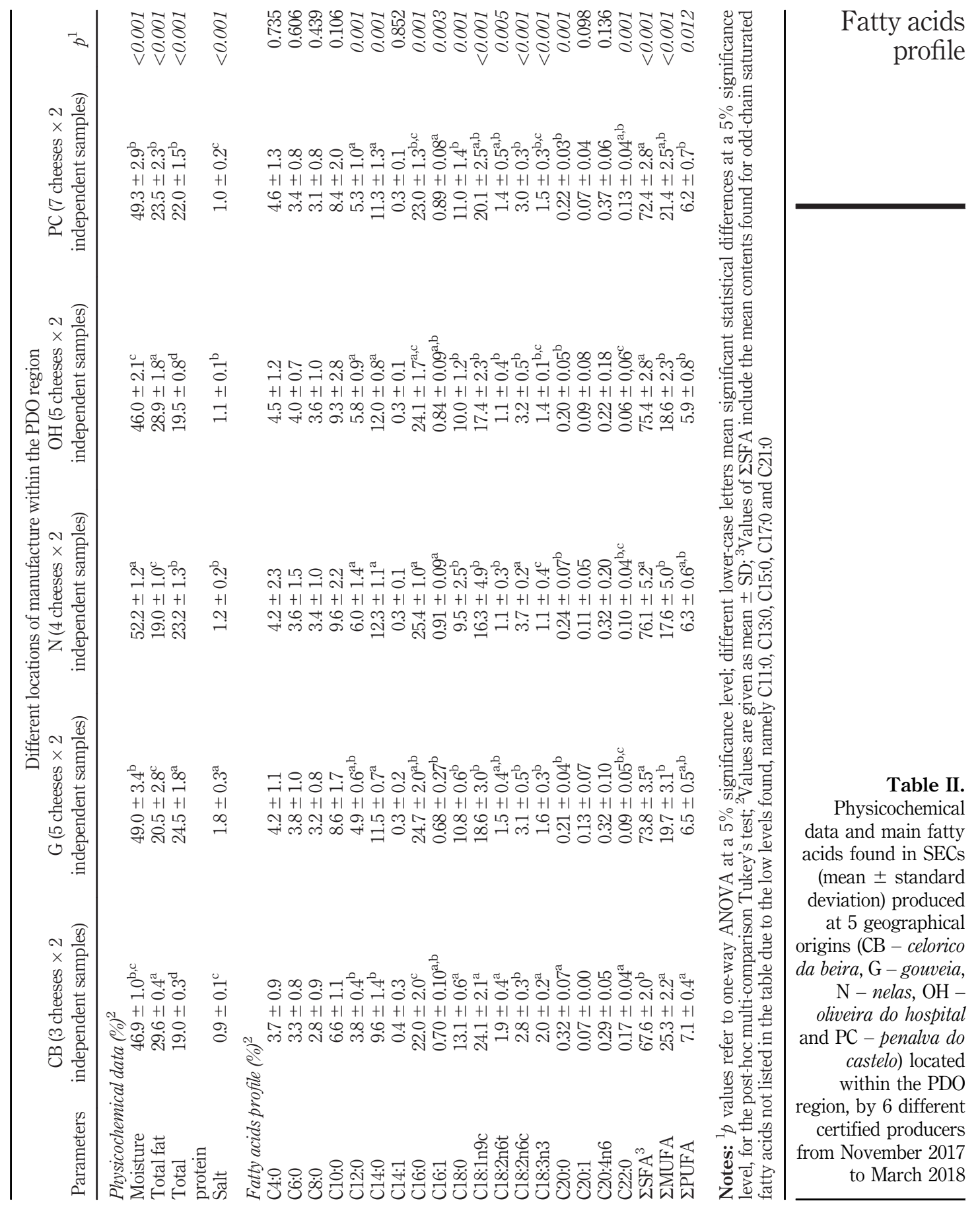


NFS

Table III.

Physicochemical data and main fatty acids found in SECs (mean \pm standard deviation) produced at 5 different dates (2017: November and december; 2018: January, february and march) in 5 geographical origins located within the PDO region, by 6 different local certified producers

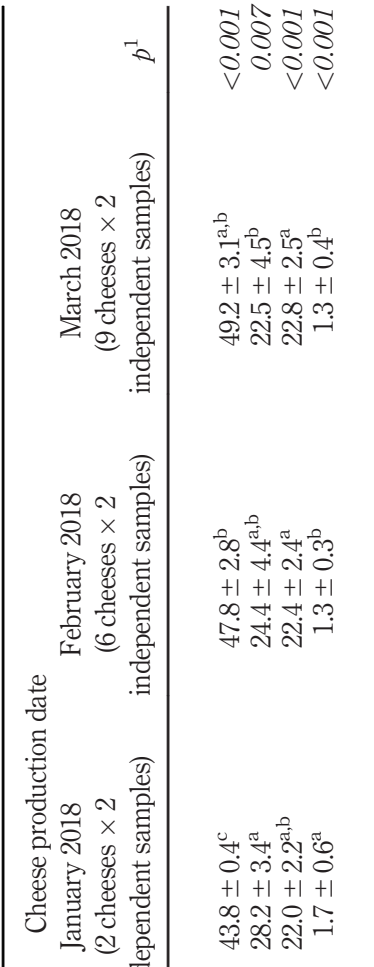

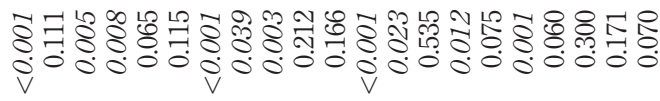

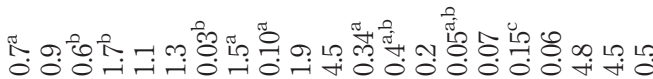
$+1+1+1+1+1+1+1+1+1+1+1+1+1+1+1+1+1+1+1+1+1$

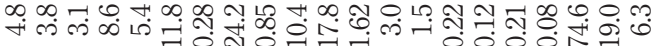

ปู $+1+1+1+1+1+1+1+1+1+1+1+1+1+1+1+1+1+1+1+1+1$

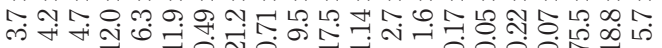

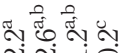

ติ $+1+1+1+1$

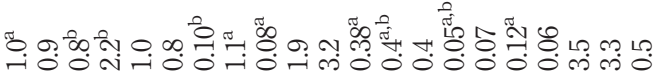
$+1+1+1+1+1+1+1+1+1+1+1+1+1+1+1+1+1+1+1+1+1$ 宊

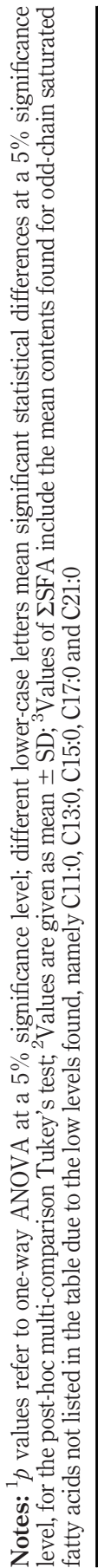


In all Serra da Estrela PDO cheeses evaluated (24 cheeses $\times 2$ independent samples) 23 fatty acids were quantified, independently of the cheese producer, geographical origin and moment of production, being the mean contents shown in Tables I-III, with the exception of the 5 odd-chain saturated fatty acids, which were detected in low levels $\left(\mathrm{C}_{11: 0}, \mathrm{C}_{13: 0}, \mathrm{C}_{15: 0}\right.$, $\mathrm{C}_{17: 0}$ and $\mathrm{C}_{21: 0}$ ). The FFA profiles were in line with those previously established for this traditional cheese by other authors (Carocho et al., 2016a, 2016b;Macedo and Malcata, 1996; Partidário et al., 1998). Overall, 15 saturated fatty acids $\left(\mathrm{C}_{4: 0}, \mathrm{C}_{6: 0}, \mathrm{C}_{8: 0}, \mathrm{C}_{10: 0}, \mathrm{C}_{11: 0}, \mathrm{C}_{12: 0}, \mathrm{C}_{13: 0}\right.$, $\mathrm{C}_{14: 0}, \mathrm{C}_{15: 0}, \mathrm{C}_{16: 0}, \mathrm{C}_{17: 0}, \mathrm{C}_{18: 0}, \mathrm{C}_{20: 0}, \mathrm{C}_{21: 0}$ and $\mathrm{C}_{22: 0}$ ), 4 monounsaturated fatty acids (MUFA) $\left(\mathrm{C}_{14: 1}, \mathrm{C}_{16: 1}, \mathrm{C}_{18: \ln 9 \mathrm{c}}\right.$ and $\left.\mathrm{C}_{20: 1}\right)$ and 4 polyunsaturated fatty acids (PUFA) $\left(\mathrm{C}_{18: 2 \mathrm{n} 6 \mathrm{t}}, \mathrm{C}_{18: 2 \mathrm{n} 6 \mathrm{c}}\right.$, $\mathrm{C}_{18: 3 \mathrm{n} 3}$ and $\mathrm{C}_{20: 4 n 6}$ ) were identified. Among the fatty acids classes, the saturated fatty acids were predominant and palmitic acid $\left(\mathrm{C}_{16: 0}\right)$ contributed most to the profile of saturated fatty acids $\left(\mathrm{C}_{4: 0}, \mathrm{C}_{6: 0}, \mathrm{C}_{8: 0}, \mathrm{C}_{10: 0}, \mathrm{C}_{12: 0}, \mathrm{C}_{14: 0}, \mathrm{C}_{16: 0}, \mathrm{C}_{18: 0}\right)$. Also, oleic acid $\left(\mathrm{C}_{18: 1 \mathrm{n} 9 \mathrm{cis}}\right)$ was the fatty acid that contributed most to the profile of unsaturated fatty acids. Similarly, the PUFA levels were predominantly constituted by linoleic acid $\left(\mathrm{C}_{18: 2 n 6 t}, \mathrm{C}_{18: 2 n 6 c}\right)$ andlinolenic acid $\left(\mathrm{C}_{18: 3 n 3}\right)$. The quantified levels of FFA are in accordance with those determined by Carocho et al. (2015, 2016a, 2016b) for this type of PDO cheese. Also, SEC fatty acids profiles were within the same order of magnitude of those found in semi-hard uncooked Italian cheese (Cabiddu et al., 2006), Manchego Spanish cheese (Gómez-Cortés et al., 2009), Chilean, French and Spanish commercial cheeses (Aguilar et al., 2014), Serbian white brined cheeses (Barać et al., 2018), Portuguese Terrincho ewe cheese (Pinho et al., 2003) or of hard ewe milk cheeses (Hernández-Ramos et al., 2018).

Fatty acids profiles of SECs (Tables I-III) were significantly influenced by cheese producer, geographical origin or moment of production, probably due to the difference in the milk used, since the FFA composition of the milk fat depends on the animals' feed, the season and the stage of lactation (Cabiddu et al., 2006;Jaramillo et al., 2008; Vera et al., 2009; Gómez-Cortés et al., 2015; Giorgio et al., 2019; Nájera et al., 2017). Furthermore, the effect of the possibly distinct handling of the curds during manufacture should be considered, since SEC is handmade (Estrada et al., 2019; Poveda et al., 2000). Cheese producer and geographical origin mostly affected the relative contents of some high chain saturated fatty acids, as well as unsaturated fatty acids (in general, $p \leq 0.007$, for one-way ANOVA). Also, total SFA, MUFA and PUFA relative abundances were also significantly influenced by cheese producer and geographical origin ( $p \leq 0.012$, for one-way ANOVA), which confirms that, although the production of this high-value PDO traditional cheese is legally regulated, differences of fatty acids contents emerged according to the cheese's producer/geographical origin. On the contrary, the moment of production seems to mostly affect the relative abundance of short, medium and high chain saturated fatty acids as well as of some unsaturated fatty acids $(p<0.044$, for one-way ANOVA) but did not influenced the relative abundance of total SFA, MUFA and PUFA $(0.070 \leq p \leq 0.300$, for one-way ANOVA).

Finally, it should be remarked that, SECs showed a relative high abundance of SFA (ranging from 67 to 76 per cent), followed by a medium content of MUFA (relative contents of 17-25 per cent) and by a low level of PUFA (varying in the range 5-7 per cent).

\subsection{Lipid quality indices: influence of origin and moment of production}

The availability of data concerning to lipid quality indices may allow having a clearer and informative knowledge regarding the nutritional and/or health impact of the consumption of dairy products. In this context, some researchers have been focussing their attention on the determination of some lipid health-related quality indices (e.g. DFA, SCFA and MCFA relative abundance as well as AI, TI and $\Sigma(\omega-6) / \Sigma(\omega-3)$ values) 
besides the fatty acids' composition of cheeses. Indeed, low values of AI, TI and $\Sigma(\omega-6) /$ $\Sigma(\omega-3)$ are highly desirable as well as higher values of DFA, SCFA and MCFA. Several researchers reported the AI values for different types of ewe cheese (0.84 for supplemented diet to 5.57 for no supplemented diets) showing that sheep diet supplementation allowed a decrease of the AI values (Cabiddu et al., 2006;Gómez-Cortés et al., 2009; Vargas-Bello-Pérez et al., 2013a, 2013b). For commercial ewe cheese, Aguilar et al. (2014) found mean AI values of 2.33-2.63, TI values varying within 2.81-3.10 and, $\Sigma(\omega-6) / \Sigma(\omega-3)$ ratios ranging between 3.79 to 6.45 , which were similar to those previously reported in the literature for ewe cheeses. Despite the relevance of lipid quality indices, namely from a health point of view, no information could be found in the literature regarding Serra da Estrela PDO cheeses. The results presented in this study provide a nutritional evaluation of the fatty acids components and their healthrelated lipid indices. All indices evaluated showed a wide variability (Figures 1-3).
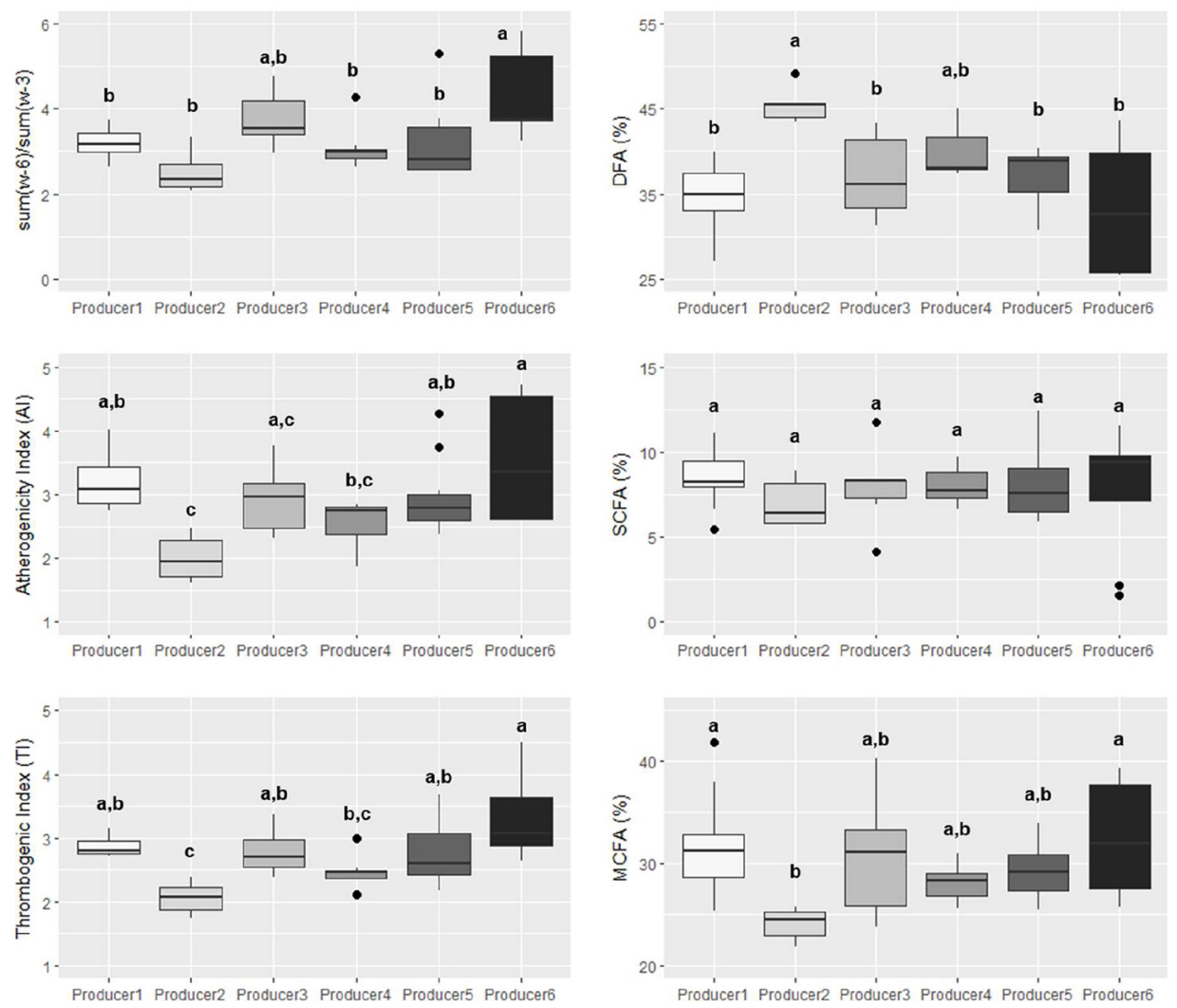

Boxplots for lipid quality indices as influenced by Serra da Estrela PDO cheese producer (Producers 1 to 6 )

Notes: AI: atherogenic index; TI: thrombogenic index; $\omega 6 / \omega 3$ ratio: $\Sigma(\omega-6) / \Sigma(\omega-3)$ ratio; MCFA: medium saturated chain fatty acids in \%; SCFA: short chain saturated fatty acids in \%; and, DFA: desirable fatty acids in \%. Different lower-case letters mean significant statistical differences at a 5\% significance level, for the post-hoc multi-comparison Tukey's test 

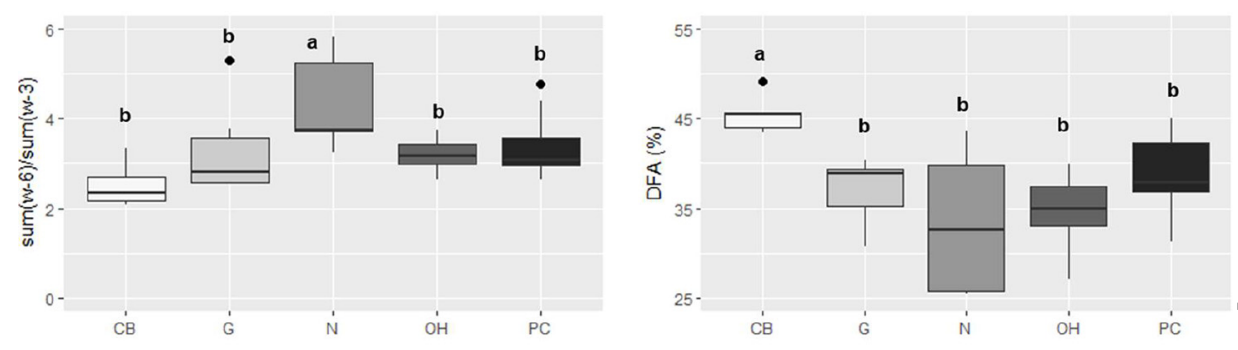

Fatty acids profile
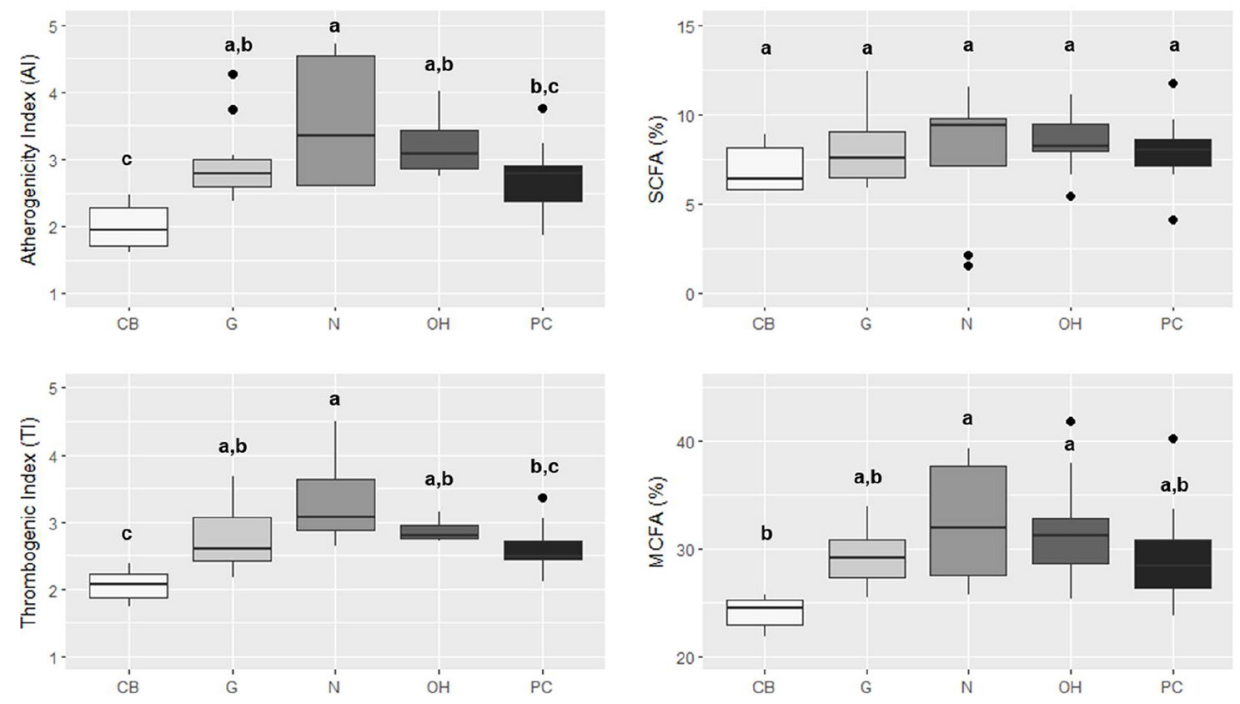

Notes: AI: atherogenic index; TI: thrombogenic index; $\omega 6 / \omega 3$ ratio: $\Sigma(\omega-6) / \Sigma(\omega-3)$ ratio; MCFA: medium saturated chain fatty acids in \%; SCFA: short chain saturated fatty acids in \%; and, DFA: desirable fatty acids in \%. Different lower-case letters mean significant statistical differences at a 5\% significance level, for the post-hoc multi-comparison Tukey's test

Figure 2.

Boxplots for lipid quality indices as influenced by Serra da Estrela PDO cheese geographical origin (municipalities of Celorico da Beira-

$\mathrm{CB}$, Gouveia - G, Nelas - N, Oliveira do Hospital-OH, and Penalva do Castelo -

Besides, from the 3 main effects evaluated, the moment of production was the one that, from a statistical point of view, had a lower influence on the studied lipid quality indices. The relative abundances of DFA varied from 25.4 to 49.1 per cent, of SCFA ranged between 1.6 and 12.4 per cent, and of MCFA within 21.9 and 41.8 per cent. From the results (Figures 1-3) emerged that cheeses from Producer $2 / \mathrm{CB}$ region possessed significantly greater DFA values and significantly lower MCFA than the other 5 certified producers under study although regarding the total samples tested this producer presented the highest fat content, which could be related to animals' fed and/ or different manufacturing practices. The AI, TI and $\Sigma(\omega-6) / \Sigma(\omega-3)$ values found for SECs also showed a wide variability, varying in mean values in $2.92 \pm 0.73,2.73 \pm 0.52$ and $3.33 \pm 0.86$, respectively. No guidelines currently exist regarding the AI and TI of dairy products, and lower indices are thought to be better for human health (Bentes et al., 2009). According to Turan et al. (2007), lower AI and TI translate into more anti- 
NFS
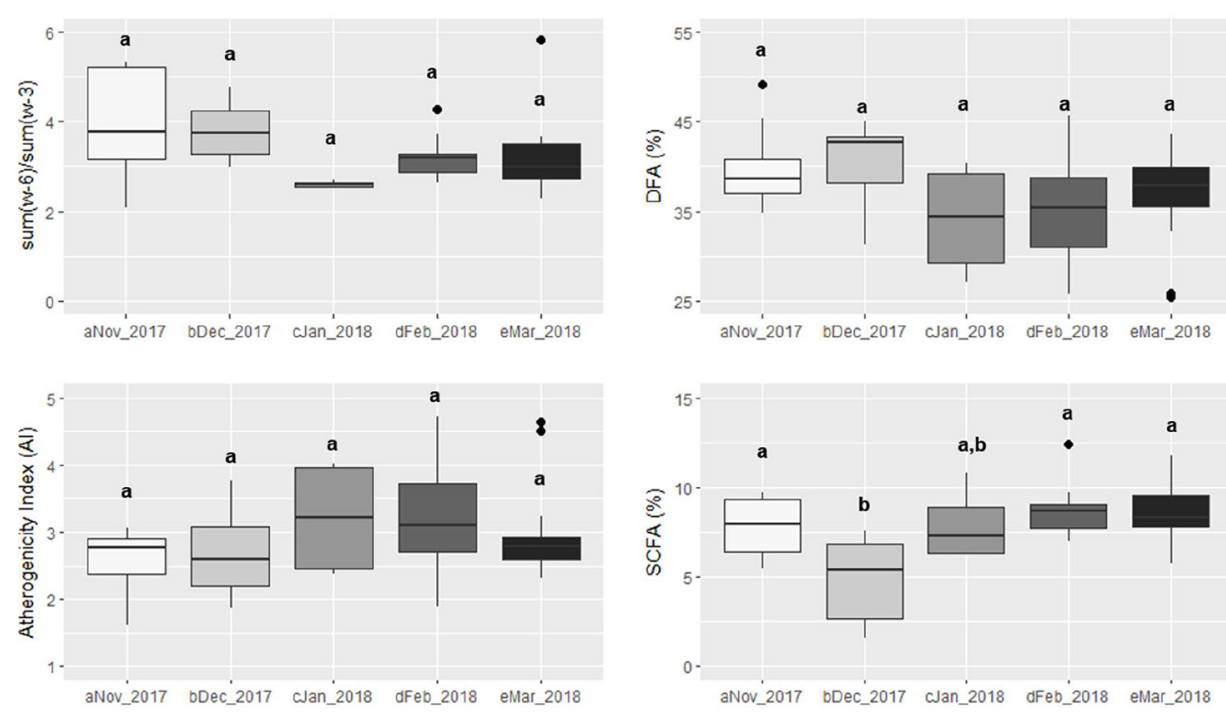

Figure 3.

Boxplots for lipid quality indices as influenced by Serra da Estrela PDO cheese production date (November 2017 to March 2018)
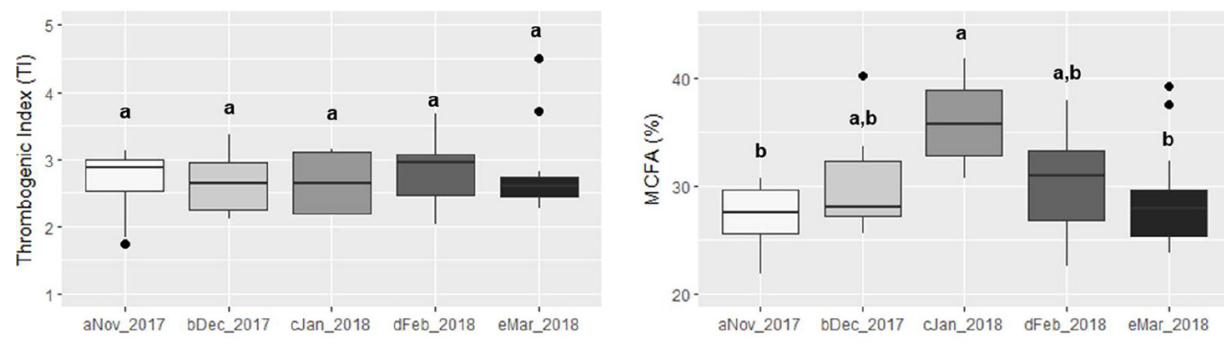

Notes: AI: atherogenic index; TI: thrombogenic index; $\omega 6 / \omega 3$ ratio: $\Sigma(\omega-6) / \Sigma(\omega-3)$ ratio;

MCFA: medium saturated chain fatty acids in \%; SCFA: short chain saturated fatty acids in \%; and, DFA: desirable fatty acids in \%. Different lower-case letters mean significant statistical differences at a 5\% significance level, for the post-hoc multi-comparison Tukey's test

atherogenic FAs and better disease prevention profiles. Nevertheless, it should be remarked that the determined levels are in accordance with the ranges previously reported by other researchers for ewe, goat and cow cheeses (Aguilar et al., 2014; Cabiddu et al., 2006; Gómez-Cortés et al., 2009; Oliveira et al., 2015; Rodrigues et al., 2012;Taboada et al., 2015;Vargas-Bello-Pérez et al., 2013a, 2013b).

Moment of manufacturing presented low $\mathrm{AI}$ and TI and the $\Sigma(\omega-6) / \Sigma(\omega-3)$ values were below recommended level (less than 4.0) thus differences observed might be attributed to differences in animal's feed (location in de region) and to the producer. As we previously considered the ewes' maintenance and the feed quality might directly influence the milk chemical and microbiological characteristics and consequently the final cheese composition (Balthazar et al., 2017; Jaramillo et al., 2008; Sanz Sampelayo et al., 2007). Also, the natural and heterogeneous microflora associated with the processing and maturation contributed to the different profiles of SEC. 


\section{Conclusions}

This work consists in a detailed study on the fatty acids composition and the related lipid health indices of SEC. SECs presented relative high abundance of SFA followed by a medium content of MUFA. We also tried to overcame the paradigm that these kind of cheeses may constitute a problem to consumers by calculating its lipid indices. The statistical significant differences found regarding the fatty acid profiles of the studied cheeses could foresee their future use to differentiate the cheese producer in different locations inside geographical origin, which may give some insights into animal feed and production management. Finally, the data from this study could be used to develop benchmark tools and strategies aiming at improving the nutritional characteristics of sheep cheese.

\section{References}

Aguilar, C., Toro-Mujica, P., Vargas-Bello-Pérez, E., Vera, R., Ugalde, C., Rodríguez, S. and Briones, I. (2014), "A comparative study of the fatty acid profiles in commercial sheep cheeses", Grasas y Aceites, Vol. 65 No. 4, p. e048.

Aro, T.L., Larmo, P.S., Backman, C., Kallio, H. and Tahvonen, R. (2005), "Fatty acids and fat-soluble vitamins in salted herring (clupea harengus) products", Journal of Agricultural and Food Chemistry, Vol. 53 No. 5, pp. 1482-1488.

Balthazar, C.F., Pimentel, T.C., Ferrão, L.L., Almada, C.N., Santillo, A., Silva, M.C., Albenzio, M., Mollakhalili, N., Mortazavian, A.M., Nascimento, J.S., Silva, M.C. and Freitas, M.Q. (2017), "Sheep milk: physicochemical characteristics and relevance for functional food development", Comprehensive Reviews in Food Science and Food Safety, Vol. 16 No. 2, pp. 247-262.

Barać, M., Kresojević, M., Špirović-Trifunović, B., Pešić, M., Vučić, T., Kostić, A. and Despotović, S. (2018), "Fatty acid profiles and mineral content of Serbian traditional white brined cheeses", Mljekarstvo, Vol. 68 No. 1, pp. 37-45.

Bentes, Á. D S., Souza, H.A.L.D. and Mendonça, X.M.F.D. (2009), "Physical and chemical characterization and lipid profile of three Amazon fish species", Revista Brasileira de Tecnologia Agroindustrial, Vol. 3 No. 2, pp. 97-108.

Cabiddu, A., Addis, M., Pinna, G., Decandia, M., Sitzia, M., Piredda, G., Pirisi, A. and Molle, G. (2006), "Effect of corn and beet pulp based concentrates on sheep milk and cheese fatty acid composition when fed mediterranean fresh forages with particular reference to conjugated linoleic acid cis-9, trans-11”, Animal Feed Science and Technology, Vol. 131 Nos 3/4, pp. 292-311.

Cadima, J., Cerdeira, J.O. and Minhoto, M. (2004), "Computational aspects of algorithms for variable selection in the context of principal components", Computational Statistics and Data Analysis, Vol. 47 No. 2, pp. 225-236.

Cadima, J. Cerdeira, J.O. Silva, P.D. and Minhoto, M. (2018), “The subselect R package”.

Calder, P.C. (2013), "Omega-3 polyunsaturated fatty acids and inflammatory processes: nutrition or pharmacology?", British Journal of Clinical Pharmacology, Vol. 75 No. 3, pp. 645-662.

Carocho, M., Barreira, J.C.M., Antonio, A.L., Bento, A., Morales, P. and Ferreira, I.C.F.R. (2015), "The incorporation of plant materials in 'Serra da Estrela' cheese improves antioxidant activity without changing the fatty acid profile and visual appearance", European Journal of Lipid Science and Technology, Vol. 117 No. 10, pp. 1607-1614.

Carocho, M., Barreira, J.C.M., Bento, A., Fernández-Ruiz, V., Morales, P. and Ferreira, I.C.F.R. (2016a), "Chestnut and lemon balm based ingredients as natural preserving agents of the nutritional profile in matured 'Serra da Estrela' cheese”, Food Chemistry, Vol. 204, pp. 185-193.

Carocho, M., Barros, L., Barreira, J.C.M., Calhelha, R.C., Soković, M., Fernández-Ruiz, V., Buelga, C.S., Morales, P. and Ferreira, I.C. (2016b), "Basil as functional and preserving ingredient in 'Serra da Estrela' cheese", Food Chemistry, Vol. 207, pp. 51-59. 
Cockbain, A.J., Toogood, G.J. and Hull, M.A. (2012), "Omega-3 polyunsaturated fatty acids for the treatment and prevention of colorectal cancer", Gut, Vol. 61 No. 1, pp. 135-149.

Correia, P., Vitor, A., Tenreiro, M., Correia, A.C., Pinto, A., Correia, P., Madanelo, J., Vacas, M. and Guiné, R. (2014), "Influence of different processing parameters in physical and sensorial properties of serra De estrela cheese", Journal of Hygienic Engineering and Design, Vol. 8, pp. 135-140.

Estrada, O., Ariño, A. and Juan, T. (2019), "Salt distribution in raw sheep milk cheese during ripening and the effect on proteolysis and lipolysis", Foods, Vol. 8 No. 3, p. 100.

Fattore, E. and Massa, E. (2018), "Dietary fats and cardiovascular health: a summary of the scientific evidence and current debate", International Journal of Food Sciences and Nutrition, Vol. 69 No. 8, pp. 916-927.

Garaffo, M.A., Vassallo-Agius, R., Nengas, Y., Lembo, E., Rando, R., Maisano, R., Dugo, G. and Giuffrida, D. (2011), "Fatty acids profile, atherogenic (IA) and thrombogenic (IT) health lipid indices, of raw roe of blue fin tuna (thunnus thynnus L.) and their salted product "bottarga", Food and Nutrition Sciences, Vol. 02 No. 7, pp. 736-743.

Giorgio, D., Di Trana, A., Di Napoli, M.A., Sepe, L., Cecchini, S., Rossi, R. and Claps, S. (2019), "Comparison of cheeses from goats fed 7 forages based on a new health index", Journal of Dairy Science, Vol. 102 No. 8.

Gómez-Cortés, P., Bach, A., Luna, P., Juárez, M. and de la Fuente, M.A. (2009), "Effects of extruded linseed supplementation on n-3 fatty acids and conjugated linoleic acid in milk and cheese from ewes", Journal of Dairy Science, Vol. 92 No. 9, pp. 4122-4134.

Gómez-Cortés, P., Viturro, E., Juárez, M. and De La Fuente, M.A. (2015), “Alternative to decrease cholesterol in sheep milk cheeses”, Food Chemistry, Vol. 188, pp. 325-327.

Guiné, R.P.F., Tenreiro, M.I.C., Correia, A.C., Correia, P.M.R. and Barracosa, P. (2016), "Analysis of factors influencing the physical, chemical and sensorial properties of Serra da Estrela cheeses", Journal of Food Measurement and Characterization, Vol. 10 No. 3, pp. 643-657.

Hernández-Ramos, P.A., Vivar-Quintana, A.M. and Revilla, I. (2018), "Estimation of somatic cell count levels of hard cheeses using physicochemical composition and artificial neural networks", Journal of Dairy Science, Vol. 102 No. 2, pp. 1014-1024.

Hirigoyen, D., de los Santos, R., Calvo, M., González-Revello, A. and Constantin, M. (2018), "Chemical composition and seasonal changes in the fatty acid profile of uruguayan "Colonia " cheeses", Grasas y Aceites, Vol. 69 No. 2, pp. 1-8.

Jaramillo, D.P., Zamora, A., Guamis, B., Rodríguez, M. and Trujillo, A.J. (2008), "Cheesemaking aptitude of two Spanish dairy ewe breeds: changes during lactation and relationship between physicochemical and technological properties", Small Ruminant Research, Vol. 78 Nos 1/3, pp. 48-55.

Legrand, P. and Rioux, V. (2015), "Specific roles of saturated fatty acids: beyond epidemiological data", European Journal of Lipid Science and Technology, Vol. 117 No. 10, pp. 1489-1499.

Lottenberg, A.M., Afonso, M., da, S., Lavrador, M.S.F., Machado, R.M. and Nakandakare, E.R. (2012), "The role of dietary fatty acids in the pathology of metabolic syndrome", The Journal of Nutritional Biochemistry, Vol. 23 No. 9, pp. 1027-1040.

Macedo, A.C. and Malcata, F.X. (1996), "Changes in the major free fatty acids in serra cheese throughout ripening", International Dairy Journal, Vol. 6 Nos 11/12, pp. 1087-1097.

Macedo, A.C., Tavares, G. and Malcata, F.X. (2004), "Influence of native lactic acid bacteria on the microbiological, biochemical and sensory profiles of Serra da Estrela cheese", Food Microbiology, Vol. 21 No. 2, pp. 233-240.

Nájera, A.I., Bustamante, M.A., Albisu, M., Valdivielso, I., Amores, G., Mandaluniz, N., Arranz, J., Barron, L.J.R. and de Renobales, M. (2017), "Fatty acids, vitamins and cholesterol content, and sensory properties of cheese made with milk from sheep fed rapeseed oilcake", Journal of Dairy Science, Vol. 100 No. 9, pp. 6962-6971. 
Oliveira, R., Faria, M., Silva, R., Bezerra, L., Carvalho, G., Pinheiro, A., Simionato, J. and Leão, A., (2015), "Fatty acid profile of milk and cheese from dairy cows supplemented a diet with palm kernel cake", Molecules, Vol. 20 No. 8, pp. 15434-15448.

Osmari, E.K., Cecato, U., Macedo, F.A.F. and Souza, N.E. (2011), "Nutritional quality indices of milk fat from goats on diets supplemented with different roughages", Small Ruminant Research, Vol. 98 Nos 1/3, pp. 128-132.

Partidário, A.M., Barbosa, M. and Boas, L.V. (1998), "Free fatty acids, triglycerides and volatile compounds in Serra da Estrela cheese-changes throughout ripening", International Dairy Journal, Vol. 8 Nos 10/11, pp. 873-881.

Pinho, O., Ferreira, I.M.P.L.V.O. and Ferreira, M.A. (2003), "Quantification of short-chain free fatty acids in 'terrincho' ewe cheese: intravarietal comparison”, Journal of Dairy Science, Vol. 86 No. 10, pp. 3102-3109.

Poppitt, S.D., Koegh, G.F., Mulvey, T.B., McArdle, B.H., MacGibbon, A.K.H. and Cooper, G.J.S. (2002), "Lipid-loweing effects of a modified butter-fat: a controlled intervention trial in healthy men", European Journal of Clinical Nutrition, Vol. 56 No. 1, pp. 64-71.

Poveda, J.M., Pérez-Coello, M.S. and Cabezas, L. (2000), "Seasonal variations in the free fatty acid composition of manchego cheese and changes during ripening", European Food Research and Technology, Vol. 210 No. 5, pp. 314-317.

Reis Lima, M.J., Fontes, L. and Pinto, A. (2019), "Nutritional and microbiological composition of serra estrela cheese: a paradigm to overcome", International Journal of Clinical Nutrition and Dietetics Nutritional, Vol. 5 No. 140, p. 5.

Rodrigues, D., Rocha-Santos, T.A.P., Gomes, A.M., Goodfellow, B.J. and Freitas, A.C. (2012), "Lipolysis in probiotic and synbiotic cheese: the influence of probiotic bacteria, prebiotic compounds and ripening time on free fatty acid profiles", Food Chemistry, Vol. 131 No. 4, pp. 1414-1421.

Sanz Sampelayo, M.R., Chilliard, Y., Schmidely, P. and Boza, J. (2007), "Influence of type of diet on the fat constituents of goat and sheep milk", Small Ruminant Research, Vol. 68 Nos 1/2, pp. 42-63.

Simopoulos, A.P. (2002), "The importance of the ratio of omega-6/omega-3 essential fatty acids", Biomedicine and Pharmacotherapy, Vol. 56, pp. 365-379.

Taboada, N., Van Nieuwenhove, C., Alzogaray, S.L. and Medina, R. (2015), "Influence of autochthonous cultures on fatty acid composition, esterase activity and sensory profile of argentinean goat cheeses", Journal of Food Composition and Analysis, Vol. 40, pp. 86-94.

Terada, S., Yamamoto, S., Sekine, S. and Aoyama, T. (2012), "Dietary intake of medium- and long-chain triacylglycerols ameliorates insulin resistance in rats fed a high-fat diet”, Nutrition, Vol. 28 No. 1, pp. 92-97.

Turan, H., Sonmez, G. and Kaya, Y. (2007), "Fatty acid profile and proximate composition of the thornback ray (raja clavata, L. 1758) from the sinop coast in the black sea", Journal of Fisheries Sciences.Com, Vol. 1 No. 2, pp. 97-103.

Ulbricht, T.L.V. and Southgate, D.A.T. (1991), "Coronary heart disease: seven dietary factors”, The Lancet, Vol. 338 No. 8773, pp. 985-992.

Vargas-Bello-Pérez, E., Vera, R.R., Aguilar, C., Lira, R., Peña, I. and Fernández, J. (2013a), “Feeding olive cake to ewes improves fatty acid profile of milk and cheese", Animal Feed Science and Technology, Vol. 184 Nos 1/4, pp. 94-99.

Vargas-Bello-Pérez, E., Vera, R.R., Aguilar, C., Lira, R., Peña, I., Valenzuela, A. and Cerda, H. (2013b), "Effect of dietary inclusion of lampante olive oil on milk and cheese fatty acid profiles of ewes", Grasas y Aceites, Vol. 64 No. 3, pp. 295-303.

Venables, W.N. and Ripley, B.D. (2002), Modern Applied Statistics with S-Plus, Springer, available at: https://doi.org/10.2307/2685660.

Vera, R.R., Aguilar, C. and Lira, R. (2009), "Differentiation of sheep milk and cheese based on quality and composition”, Ciencia e Investigacion Agraria, Vol. 36 No. 3, pp. 307-328. 
Maria João Reis Lima can be contacted at: mjoaolima@esav.ipv.pt

\section{Author affiliations}

Maria João Reis Lima, Center for Studies in Education, Technology and Health (CI\&DETS) and Research Centre for Natural Resources, Environment and Society (CERNAS), Polytechnic Institute of Viseu, Viseu, Portugal and Department of Food Science, Agrarian School of Viseu, Polytechnic Institute of Viseu, Viseu, Portugal

Luisa Fontes, Department of Food Science, Agrarian School of Viseu, Polytechnic Institute of Viseu, Viseu, Portugal

Hamdi Bahri, Centro de Investigação de Montanha (CIMO), Instituto Politécnico de Bragança, Bragança, Portugal

Ana C.A. Veloso, Instituto Politécnico de Coimbra, ISEC, DEQB, Coimbra, Portugal and CEB - Centre of Biological Engineering, University of Minho, Braga, Portugal

Edite Teixeira-Lemos, Center for Studies in Education, Technology and Health (CI\&DETS) and Research Centre for Natural Resources, Environment and Society (CERNAS), Polytechnic Institute of Viseu, Viseu, Portugal and Department of Food Science, Agrarian School of Viseu, Polytechnic Institute of Viseu, Viseu, Portugal, and

António M. Peres, Centro de Investigação de Montanha (CIMO), Instituto Politécnico de Bragança, Bragança, Portugal and Laboratory of Separation and Reaction Engineering - Laboratory of Catalysis and Materials (LSRE-LCM), ESA, Instituto Politécnico de Bragança, Bragança, Portugal

For instructions on how to order reprints of this article, please visit our website: 